\title{
Assesment of morphological changes of articular eminence and condyle using CBCT
}

\author{
Sravya Vemareddy ${ }^{1 *}$, A. Kannan ${ }^{2}$, P. Raghuram ${ }^{3}$, N. Kannan ${ }^{4}$ \\ ${ }^{1}$ Senior Lecturer, ${ }^{2}$ Professor, ${ }^{3,4}$ Professor and Head, Dept. of Oral Medicine \& Radiology, ${ }^{1,4}$ Narayana Dental College and Hospital, \\ Nellore, Andhra Pradesh, ${ }^{2,3}$ S.R.M Dental College, Chennai, Tamil Nadu, India \\ *Corresponding Author: Sravya Vemareddy \\ Email: sravyavemareddy@gmail.com
}

\begin{abstract}
Objectives: To measure the inclination 1. Height of articular eminence using CBCT; 2 . To measure the length and width of condyles using CBCT. 3. To evaluate and compare above changes in pain and non painful joints.

Aim: The aim of the present study is to assess the morphological changes of articular eminence and condyle in temporomandibular joint disorder patients.

Materials and Methods: This study was conducted on 50 patients (i.e.100 joints), in which 23 are males and the rest 27 are females. These 50 patients are divided into two groups, in which, patients with painful joints are considered as study group and non painful joints were kept as control group.

Statistical Analysis and Results: Independent sample t-test was used to determine the differences in height and inclination of articular eminence and condylar length and width. Pearson correlation coefficient used to find the relation between two quantitative variables of articular eminence height and inclination with condylar width and length. There exists no difference in pain and non painful joints in TMJ patients $(p>0.05)$.

Conclusion: In the present study there were no significant changes in morphology of articular eminence and condyle in pain and non painful joints.
\end{abstract}

Keywords: Articular eminence, Condyle, CBCT, TMDs, TMJ, Imaging.

\section{Introduction}

The temporomandibular joint (TMJ) is a ginglymoarthroidal joint which permits movements over the surfaces and achieves the mandibular functions with a dynamic balance mechanism. The superior surface of the joint is formed by glenoid fossa and inferior surface by the head of the condyle. Tempromandibular joint disorders (TMDs) are a collective entity describing number of clinical problems that involve Muscles of mastication, temporomandibular joint and associated structures or both. There are several classifications used in view of the fact since decades, of which widely used classification is Research Diagnostic Criteria (RDC). This criteria clinically evaluates TMD conditions, pain related scale with disability and psychological status in association with TMD. ${ }^{1}$ The articular eminence is a part of the temporal bone on which the condylar process slides during mandibular movements. The inclination of eminence varies among people and it dictates the path of condylar movement as well as the degree of rotation of the disc over the condyle. ${ }^{2}$ The steepness of articular eminence is an etiological factor in the development of disk displacement. The normal value of inclination of articular eminence lies between 30 to 60 degrees. $^{3}$ It has been claimed that the biomechanical characteristics of the joints change due to differences in the shape of the eminence and steep eminence plays a key role in the development of disc displacement. ${ }^{4}$ Mandibular condyle being part of temporomandibular joint undergoes various morphological changes and remodelling to accommodate developmental variations, malocclusion, trauma and other developmental abnormalities and in TMD. ${ }^{5,6}$ Imaging of morphological changes of articular eminence and condylar changes is crucial in understanding, diagnosis and management of temporomandibular joint disorders. Historically several imaging modalities are used for TMJ which include conventional panoramic radiograph, TMJ projections. These modalities have limited use as they cause superimpositions of images. $^{7}$ Advanced imaging modalities like CT and MRI gives a very good insite into the changes associated with hard and soft tissues of temporomandibular joint respectively. These modalities have a drawback of high radiation exposure and are expensive with limited use in dentistry. CBCT (Cone Beam Computed Tomography) as a new imaging modality with low dose, low cost and good patient acceptance, spatial resolution of osseous structures has gained importance in oral and maxillo-facial radiology. ${ }^{8}$ There are limited studies in the literature that used CBCT for the assessment of articular eminence inclination, height and condylar length and width which are frequently associated with temporomandibular joint disorder.

The present study was undertaken to assess the morphological changes of articular eminence inclination, height, condylar length and width of TMJ, in patients with and without tenderness using CBCT, so that the application of CBCT can be extended in the diagnosis and management of temporomandibular joint disorders.

\section{Materials and Methods \\ Patients}

Following the approval of the Ethical and scientific committees of SRM university, this study was conducted in the department of Oral Medicine and Radiology at SRM Dental College, Ramapuram, Chennai, during the period February 2013-July 2015. Patients aged between 18 and 45 years with clinical signs and symptoms of 
temporomandibular joint disorders based on the Research Diagnostic Criteria were subjected to the study. The symptoms include unilateral or bilateral pain, with or without clicking sound, subluxation, and hypo mobility were included in the study. Whereas, patients having preexisting problems in the TMJ or diseases likely to affect the TMJ such as congenital craniofacial abnormalities(condylar hypoplasia, condylar hyperplasia), rheumatoid arthritis, orthodontic treatment, infectious temporomandibular joint diseases, and patients during pregnancy were excluded from the study. This study was conducted on 50 patients (i.e.100 joints), in which 23 are males and the rest 27 are females. These 50 patients are divided into two groups, in which, patients with painful joints are considered as study group and non painful joints were kept as control group.

\section{Imaging procedures}

The cone beam images were performed CBCT MACHINE KODAK 9500 with the following configuration was used, in which, the tube voltage of $90 \mathrm{kV}$ and $10 \mathrm{~mA}$, tube focal spot $0.7 \mathrm{~mm}$ (IEC 336) and the detectors comprises amorphous silicon flat panel, with exposure time of 10.8 seconds. The field was Large -field view program $18 \mathrm{~cm} \times 20 \mathrm{~cm}$ and the Voxel size $300 \mu \mathrm{m} \times 300 \mu \mathrm{m} \times 300 \mu \mathrm{m}$. The patients were placed in the standing position so that Frankfort Horizontal plane is parallel to the floor, with their head within the rotating gantry of the $\mathrm{x}$ ray tube. The $\mathrm{x}$-ray detectors performed at $360^{\circ}$ rotation around the head of the patient. The images were evaluated in CS 3D Imaging Software version 1.10. To obtain images of articular eminence inclination and height, one of the axial views on which the condylar processes were seen with their widest mediolateral extent was used as a reference view for secondary reconstruction. The sagittal slices of TMJ were performed perpendicular to the long axis of the condylar process. The central sagittal slice measurements were chosen. The view of the eminence in the central slice is the steepest part and gives the best representation to measure the inclination and height. Morphology of the condyle was categorized both in the sagittal and coronal plane. The coronal slices were performed parallel to the long axis of the condyle and sagittal slices were performed perpendicular to the coronal slice. The frontal and lateral view of condyle is chosen as the best representation to measure width and length respectively.

\section{Methods}

Measurements belonging to the articular eminence and condyle were performed on the slices defined above.

The eminence inclination is measured by establishing angle between Frankfort (X) horizontal plane and a line passing through lowest point of articular eminence (L) and a highest point of glenoid fossa $(\mathrm{H})$.

The eminence height is measured by establishing perpendicular line between highest point of fossa $(h)$ and lowest part of articular eminence $(l)$.

Condylar measurements were done three dimensionally in such a way by establishing a line between the most
medial(M) and lateral(L) points to measure the width of the condyle, whereas the length of the condyle is measured by establishing a line between the most anterior(A) to posterior points $(\mathrm{P})$ of the condyle.

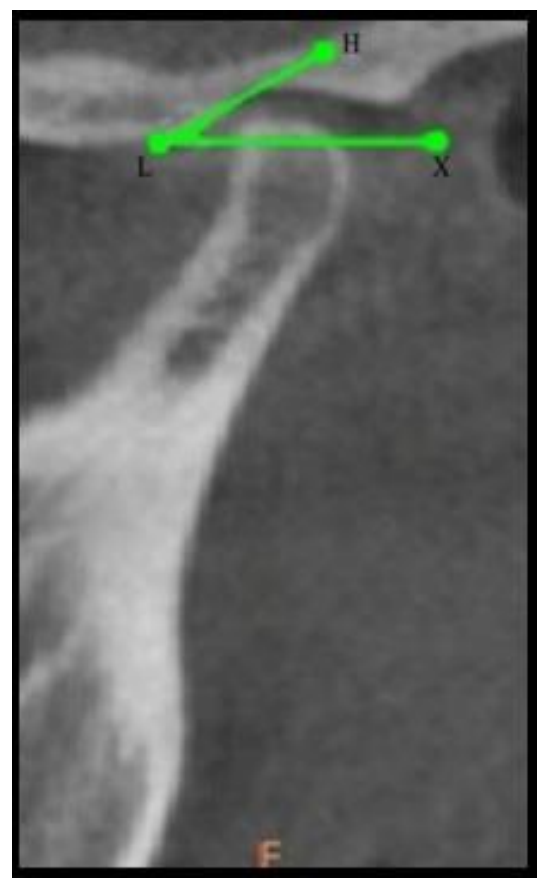

Fig. 1: Measurement of articular eminence inclination

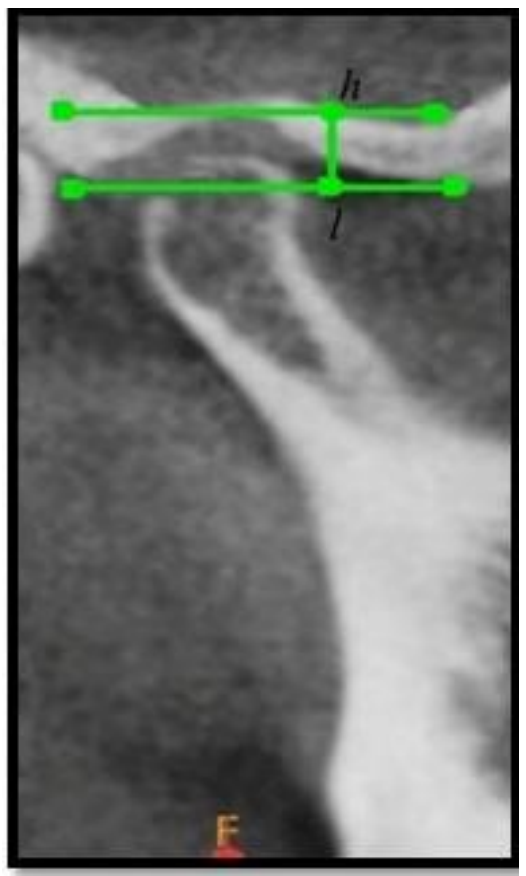

Fig. 2: Measurement of articular eminence height 


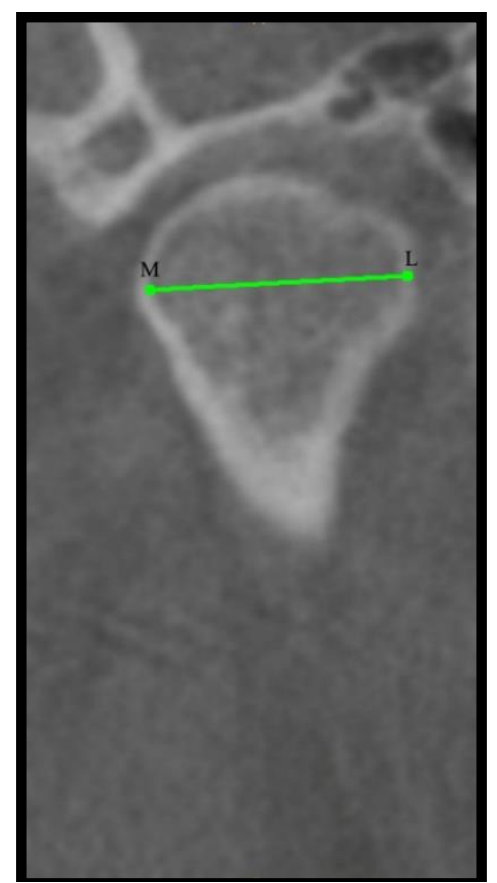

Fig. 3: Measurement of Medio-lateral width of the Condyle

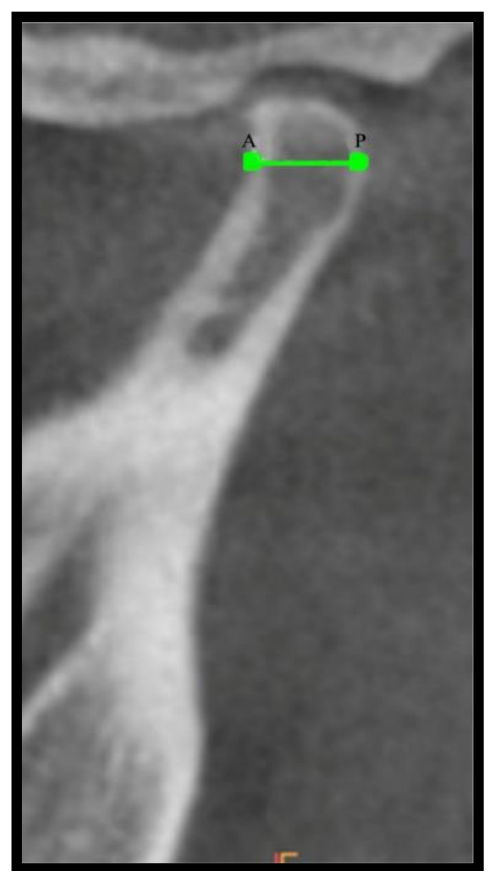

Fig. 4: Measurement of Anterioposterior length of Condyle

\section{Statistical Analysis and Results}

The Normality tests Kolmogorov-Smirnov and Shapiro Wilks tests results showed that the variables follow Normal distribution. Independent sample t-test used to determine the differences in height and inclination of articular eminence and condylar length and width. Pearson correlation coefficient used to find the relation between two quantitative variables of articular eminence height and inclination with condylar width and length.

Inclination and height of articular eminence and condylar length and width between pain and non painful joints were not significant $(\mathrm{P}>0.05)$ (Table 1) The Pearson Correlation between articular eminence inclination and condyle length \& width is not significant $(\mathrm{P}>0.05)$. The Correlation between articular eminence height and condyle length is not significant $(\mathrm{P}>0.05)$ but significant with condyle width $(\mathrm{P}<0.05)($ Table 2$)$

Table 1: Comparison of mean values between pain and non painful joint

\begin{tabular}{|c|c|c|c|c|c|c|}
\hline Variables & Pain & $\mathbf{N}$ & Mean & $\begin{array}{l}\text { Std. } \\
\text { Dev }\end{array}$ & $\begin{array}{c}\text { t- } \\
\text { Value }\end{array}$ & $\begin{array}{c}\text { P- } \\
\text { Value }\end{array}$ \\
\hline \multirow{2}{*}{$\begin{array}{l}\text { Articular eminence } \\
\text { inclination }(\mathrm{mm})\end{array}$} & $\begin{array}{l}\text { No } \\
\text { pain }\end{array}$ & 50 & 38.000 & 7.4386 & \multirow{2}{*}{0.234} & \multirow{2}{*}{0.815} \\
\hline & Pain & 50 & 37.647 & 7.6232 & & \\
\hline \multirow{2}{*}{$\begin{array}{l}\text { Articular eminence } \\
\text { height (mm) }\end{array}$} & $\begin{array}{c}\text { No } \\
\text { pain }\end{array}$ & 50 & 6.737 & 1.1759 & \multirow[t]{2}{*}{0.119} & \multirow[t]{2}{*}{0.906} \\
\hline & Pain & 50 & 6.767 & 1.3356 & & \\
\hline \multirow{2}{*}{$\begin{array}{l}\text { Condylar length } \\
(\mathrm{mm})\end{array}$} & $\begin{array}{l}\text { No } \\
\text { pain }\end{array}$ & 50 & 6.741 & .9717 & \multirow[t]{2}{*}{1.723} & \multirow[t]{2}{*}{0.088} \\
\hline & Pain & 50 & 6.371 & 1.1645 & & \\
\hline \multirow{2}{*}{$\begin{array}{l}\text { Condylar width } \\
(\mathrm{mm})\end{array}$} & $\begin{array}{l}\text { No } \\
\text { pain }\end{array}$ & 50 & 17.265 & 2.6580 & \multirow[t]{2}{*}{0.527} & \multirow[t]{2}{*}{0.599} \\
\hline & Pain & 50 & 17.533 & 2.4258 & & \\
\hline
\end{tabular}

Table 2: Pearson Correlation between variables in painful joint

\begin{tabular}{|l|c|c|c|}
\hline \multicolumn{2}{|l|}{ Painful joint } & $\begin{array}{c}\text { Condyle } \\
\text { length }\end{array}$ & $\begin{array}{c}\text { Condyle } \\
\text { width }\end{array}$ \\
\hline $\begin{array}{l}\text { Articular inclination } \\
(\mathrm{mm})\end{array}$ & Correlation & -.040 & .185 \\
\cline { 2 - 4 } & P-Value & .778 & .193 \\
\cline { 2 - 4 } & $\mathrm{N}$ & 50 & 50 \\
\hline \multirow{3}{*}{ Articular height $(\mathrm{mm})$} & Correlation & -.002 & .291 \\
\cline { 2 - 4 } & P-Value & .988 & .038 \\
\cline { 2 - 4 } & $\mathrm{N}$ & 50 & 50 \\
\hline
\end{tabular}

\section{Discussion}

Many researchers have been carried out in comparing the painful and non-painful joints in par with the morphological changes. However, the application of CBCT in such cases in determining the alterations in the shapes of the articular eminence and the condylar component aids in identifying the disorder. Due to the close relationship between the form and functions of the TMJ, this study is impeccable in correlating the structural changes of the joint. Based on the anatomical data, this study implies significant correlations among the inclination and height of the eminence, changes in the condylar head. This study also confirms the functional loads, arising from the biting forces exerted on the skeletal components of TMJ which include eminence and condyle by altering the morphology of these structures ${ }^{9,5}$ due to which condyle shows more changes in the mediolateral direction than anterioposterior. ${ }^{5}$

The conventional methods have limitations due to superimposition of the adjacent temporal bone which influences the observations and resulted in erratum. The choice of using CBCT is preferred rather CT to evaluate the osseous structures because of high radiation exposure caused by $\mathrm{CT}$ scan and also its limitations in evaluating the TMJ. Beyond all the advantages CBCT offers cost effective 
investigation and also versatile for the clinicians to measure the angles and distance without any distortion and superimposition. ${ }^{10-15}$

To obtain the view of eminence, central slice is ideal to measure the inclination and height. ${ }^{16-18}$ When the inclination of the articular eminence varies between 30 and 60 , it is considered as normal. If inclination is less than $30^{\circ}$ and exceeding 60 , is considered as flat and steep respectively. Meanwhile the condyle is best seen in coronal and sagittal slices for measuring the width in mediolateral direction and length in the Anterioposterior direction in the condyle. ${ }^{19-22}$

According to Sullun et $\mathrm{al}^{23}$ when steeper is the inclination and higher tuberculum articulaire predispose to the development of disk displacement with reduction and flattening of the eminence may progress with time, However A- is berg et $\mathrm{al}^{4}$ indicated steep articular eminence is one of the etiological factors for disc displacement. He stated that the steepness of the eminence decreases due to remodeling or degeneration of the bone resulted from internal derangement. ${ }^{24,18}$

In this study there was no significant discrimination of the morphological measurements between pain and nonpainful joint, which had been substantiated in the literature by Shoaleh Shahidi et a ${ }^{25}$ and Meryem etoz et al. ${ }^{26}$ Similar Proposal given by Sumbullu et $\mathrm{al}^{2}$ denoted that difference in articular eminence inclination, height are insignificant.

The correlation between articular eminence height and condylar width was significant, perhaps the functional remodeling of the condyle must have altered the morphology of eminence and height of the fossa. Katsavrias EG et $\mathrm{al}^{27}$ has supported the concept of functional adaptive changes of the TMJ skeletal elements and the changes in condyle head were mostly seen in mediolateral than in the anterioposterior.

\section{Conclusion}

As the soft tissue components are usually taken into account in many studies, this study has been conducted to observe the skeletal morphological changes in patients with TMJ pain using CBCT. Though there were no significant changes in morphology of articular eminence and condyle in pain and non-painful joints, the duration of pain and other symptoms were not taken into consideration. However if other symptoms of TMJ along are taken into account, the results may be remarkable significant. No doubt CBCT has benefits by means of less radiation exposure to the patient and very good tool to assess the osseous changes by the clinician.

\section{Source of funding}

None.

\section{Conflict of interest}

None.

\section{References}

1. Schiffma. Diagnostic Criteria for Temporomandibular Joint Disorders (DC/TMD) for clinical and research applications: Recommendations for International RDC/TMD Consortium network and Oro facial pain special interest group 2014volume 28 number 1.

2. MA Sumbullu Radiological examination of the articular eminence morphology using cone beam CT. Dentomaxillofac Radiol 2012;41:234-40.

3. Elias G. Katsiavrias Changes in Articular Eminence Inclination During the Craniofacial Growth Period Angles orthodontics. 2002;72;258-64.

4. Yan-Fang Ren steepness of the articular eminence in the Temporomandibular joint Tomographic comparison between asymptomatic volunteers with normal disk position and patients with disk displacement. Oralsug Oralmed Oralpath 1995;80:258-66.

5. Hegde Morphological and Radiological Variations of Mandibular Condyles in Health and Diseases: A Systematic Review. J Dent 2013;3:1.

6. Anuna Laila Mathew. Condylar Changes and Its Association with Age, TMD, and Dentition Status: A Cross-Sectional Study. Int J Dent 2011, Article ID 413639, 7 pages.

7. Barghan Application of cone beam computed tomography for assessment of the temporomandibular joints. Aust Dent $J$ 2012;57:(1 Suppl):109-18.

8. JB Ludlow Dosimetry of 3 CBCT devices for oral and maxillofacial radiology: CB Mercury, New Tom 3G and iCAT. Dent Maxillofac Radiol 2006;35.

9. O'Ryan F, Epker BN. Temporomandibular joint function and morphology: observations on the spectra of normalcy. Oral Surg Oral Med Oral Pathol 1984;58:272-9.

10. William C. Scarfe Clinical Applications of Cone Beam Computed Tomography in Dental Practice. J Can Dent Assoc 2006;72(1):75-80.

11. Ruben Pauwels. Effective dose range for dental cone beam computed tomography scanners. Eur J Radiol 2010.

12. K Tsiklakis. Radiographic examination of the temporomandibular joint using cone beam computed tomography. Dentomaxillofacial Radiol 2004;33:196-201.

13. M Alkhader Usefulness of cone beam computed tomography in temporomandibular joints with soft tissue pathology. Dentomaxillofac Radiol 2010;39:343-8.

14. Gary A. Estomaguio Unilateral condylar bone change, inclination of the posterior slope of the articular eminence and craniofacial morphology Orthodontic Waves 2008;67(3):1139.

15. Hintze. Cone beam CT and conventional tomography for the detection of morphological temporomandibular joint changes. Dento Maxillofac Radiol 2007;36:192-7.

16. Zahra Dalili. Assessing joint space and condylar position in the people with normal function of temporomandibular joint with cone-beam computed tomography. Dent Res J (Isfahan) 2012;9(5):607-12

17. Ichikawa J, Hara T, Tamatsu Y, Ide Y. Morphological changes in the internal structure of the articular eminence of the temporal bone during growth from deciduous to early mixed dentition. J Biomech 2007;40:3541-7.

18. Dilhan Elgüy. Articular Eminence Inclination, Height, and Condyle Morphology on Cone Beam Computed Tomography Scientific World Journal Volume 2014, Article ID 761714, 6 pages.

19. Z-L Zhang. Detection accuracy of condylar bony defects in Promax 3DconebeamCT images scanned with different protocols Dentomaxillofacial Radiol (2013;4220120241.

20. ML dos Anjos Pontual. Evaluation of bone changes in the temporomandibular joint using cone beam CT. Dentomaxillofac Radiol 2012;41:24-9. 
21. H Kurita. Relationship between alteration horizontal size and bony morphological change in the mandibular condyle.

Dentomaxillofac Radiol 2003;32:355-8.

22. José Valladares Neto Mandibular condyle dimensional changes in subjects from 3 to 20 years of age using Cone-Beam Computed Tomography: A preliminary study. Dental $J$ Orthodontics 2010;15(5):172-81.

23. Sullun Morphology of the mandibular fossa and inclination of the articular eminence in patients with internal derangement and in symptom-free volunteers. Oral Surg Oral Med Oral Pathol Oral Radiol Endod 2001;92:98-107.

24. H Kurita Flattening of the articular eminence correlates with progressive internal derangement of the temporomandibular joint. Dentomaxillofac Radiol 2000;29:277-9.

25. Shoaleh Shahidi Correlation between articular eminence steepness measured with cone-beam computed tomography and clinical dysfunction index in patients with temporomandibular joint dysfunction. Oral Surg Oral Med Oral Pathol Oral Radiol 2013;116(1):91-7.

26. Meryem etoz Evaluation of bony structures on panoramic radiographs with statistical shape analysis in patients with temporomandibular joint pain and limited mouth opening Journal e dentistry.

27. Katsavrias EG Morphology of the temporomandibular joint in subjects with Class II Division 2 Malocclusions. Am J Orthod Dentofacial Orthop 2006;129(4):470-8.

How to cite this article: Vemareddy $S$, Kannan A, Raghuram P, Kannan N. Assesment of morphological changes of articular eminence and condyle using CBCT. Int J Maxillofac Imaging 2019;5(3):58-62. 